\title{
Review of 2 Decades of Aneurysm-Recurrence Literature, Part 1: Reducing Recurrence after Endovascular Coiling
}

E. Crobeddu, G. Lanzino, D.F. Kallmes, and H.J. Cloft

\begin{abstract}
SUMMARY: Angiographic recurrence following endovascular therapy is an indirect measure of the potential for hemorrhage. Because patients and physicians consider recurrence to be a suboptimal outcome with some chance of future hemorrhage, much effort has been expended to reduce the incidence of recurrence. The literature regarding aneurysm recurrence following endovascular therapy, spanning 2 decades, is extensive. We will review and summarize the effort to reduce recurrence following endovascular treatment of cerebral aneurysms.
\end{abstract}

ABBREVIATIONS: $\mathrm{Cl}=$ confidence interval; HEAL = HydroCoil for Endovascular Aneurysm Occlusion; HELPS = HydroCoil Endovascular Aneurysm Occlusion and Packing Study; ISAT = International Subarachnoid Aneurysm Trial; MAPS = Matrix and Platinum Science; PGA = polyglycolic acid; PGLA = polyglycolic/polylactic acid

D etachable coils have been used for 2 decades to treat cerebral aneurysms from an endovascular approach. Aneurysm recurrence has been noted to be a problem since the earliest application of this technology. ${ }^{1}$ While endovascular coiling of cerebral aneurysms has been a great medical advance, the issue of recurrence represents a major limitation. Because aneurysm recurrence is the primary weakness of endovascular coiling relative to surgery, much of the research regarding the endovascular treatment of aneurysms has been directed at the topic of aneurysm recurrence and its prevention. In this review, we summarize this literature regarding the effort to reduce the rate of recurrence in patients with aneurysms treated with the endovascular approach.

\section{RECURRENCE FOLLOWING PLATINUM COIL TREATMENT}

A wide range of recurrence rates for aneurysms treated with platinum coils has been reported in the literature. This literature can be confusing for numerous reasons. The period of follow-up varies among studies, and patients are often lost to follow-up. Furthermore, type and size of the aneurysms considered, imaging technique, and the definition of recurrence itself vary a great deal in published studies. Although there is much variation in methods used to assess and report recurrence rates, some clinically

From the Departments of Radiology (G.L., D.F.K., H.J.C.) and Neurosurgery (E.C., G.L., D.F.K., H.J.C.), Mayo Clinic, Rochester, Minnesota.

Please address correspondence to Harry J. Cloft, MD, PhD, Mayo Clinic, 200 SW First St, Rochester, MN 55905; e-mail: cloft.harry@mayo.edu

- Indicates open access to non-subscribers at www.ajnr.org

http://dx.doi.org/10.3174/ajnr.A3032 relevant trends are apparent. In large heterogeneous groups of patients with intracranial aneurysms treated with coil embolization, overall recurrence rates of $15 \%-34 \%$ have been reported. ${ }^{2-4}$ A recent meta-analysis of recurrence rates determined that aneurysm recurrence occurred in $20.8 \%$ (95\% CI, 19.8\%-21.9\%) and retreatment was performed in 10.3\% (95\% CI, 9.5\%-11.0\%). ${ }^{5}$

Recurrence rates clearly vary with aneurysm size and neck size. Murayama et $\mathrm{al}^{2}$ reported an overall recurrence rate of 5\% for aneurysms of $4-10 \mathrm{~mm}$ with a neck of $\leq 4 \mathrm{~mm}$. For aneurysms of $4-10 \mathrm{~mm}$ with a neck of $>4 \mathrm{~mm}$, the recurrence rate increased to $20 \%$. Large aneurysms $(10-25 \mathrm{~mm})$ have been reported to have a recurrence rate of $35 \%-50 \%$. $^{2,3}$ The recurrence rate for giant aneurysms has been reported to be $59 \%-87 \%$. $^{2,6}$

Recurrence rates are affected by rupture status., ${ }^{3,7,8}$ Unruptured aneurysms of $<9 \mathrm{~mm}$ have been reported to have a recurrence rate of $7 \%$ as opposed to ruptured aneurysms of the same size, which had a recurrence rate of $17 \%{ }^{7}$

Degree of completeness of aneurysm occlusion at the time of initial treatment is related to recurrence. ${ }^{3,9-12}$ As a corollary, aneurysm packing attenuation of $>18 \%-24 \%$ has been reported to lead to a reduced recurrence rate. ${ }^{13-15}$ One large series, however, reported no relationship between packing attenuation and recurrence. ${ }^{16}$ Packing attenuation measurements are somewhat difficult to reliably obtain because measurements of aneurysm volumes are fraught with error, especially for aneurysms with complex shapes. ${ }^{17}$ Increasing packing attenuation probably decreases the recurrence rate to some extent, but the effect of increasing packing attenuation probably plateaus at some point above $20 \%$. As aneurysm size increases, packing attenuation achievable with endovascular coiling tends to drop substan- 
tially, ${ }^{18}$ which may, in large part, account for the increased recurrence rate in larger aneurysms.

Since the advent of endovascular coiling of cerebral aneurysms, operators have tried to pack aneurysms as densely as possible with coils. However, it is critical to balance the tendency to maximize packing attenuation with the potential risks of perforation or parent artery compromise with each additional coil. Expansion of coil choices has probably improved the ability of physicians to pack more coils into a given aneurysm. Balloon remodeling probably leads to higher packing attenuation, ${ }^{19}$ as does adjunctive stent placement, which is discussed below.

The impact of location on the probability of recurrence is still unclear. Several studies showed no significant difference between anterior and posterior circulation. ${ }^{3,7,20}$ However, other studies conducted exclusively on the posterior circulation indicated higher incomplete occlusion, late reopening, and high retreatment rates. ${ }^{5,10,21-23}$ This conflicting information has been attributed to differences in evaluation methodologies and case mixtures. Bias may be a factor in that large and wide-neck anterior circulation aneurysms that have a higher propensity to recur are more frequently referred for surgery than posterior circulation aneurysms with such unfavorable morphology. ${ }^{24}$

There appear to be multiple mechanisms underlying recurrence. Coil compaction may occur from poor aneurysm packing or it may accompany aneurysm growth. ${ }^{25}$ In ruptured aneurysms, coils may extrude through the wall and into the subarachnoid space $^{26}$ recanalizing portions of the aneurysm. In aneurysms with intraluminal thrombus, coils can gradually penetrate into the thrombus, resulting in restoration of flow into the aneurysm lumen. $^{27}$

\section{TECHNOLOGY TO REDUCE RECURRENCE AND REHEMORRHAGE}

Our knowledge of the potential for angiographic recurrence following endovascular coiling has led to much research aimed at developing devices that result in fewer recurrences. These have taken several forms and are discussed below.

\section{Modified Coils}

To reduce the problem of aneurysm recurrence after bare platinum coil embolization, "modified coils" such as "bioactive" coils or coils coated with PGA, PGLA, and hydrogel were introduced. ${ }^{28}$ The concept behind these coated coils has been to promote neointimal formation with subsequent fibrosis obliterating the neck of the aneurysm and/or to increase packing attenuation. The literature on the development and early clinical experiences with modified coils was reviewed in $2009,{ }^{29}$ but in the past 2 years, the results of important multicenter studies on the efficacy of some of the coil modifications have become available.

Matrix coils (Stryker, Boston, Massachusetts) are coated with PGLA. The MAPS trial was designed to clarify whether there is a real difference in recurrence rates between Matrix coils and platinum coils. Immediate occlusion rates and recurrence rates were not significantly different between Matrix and bare platinum coils. $^{30}$
Cerecyte coils (Codman and Shurtleff, Raynham, Massachusetts) have a PGA filament running through the lumen of the primary platinum wind of the coil. In December 2007, a randomized controlled trial testing Cerecyte-versus-bare-platinum coils was initiated. ${ }^{31}$ Angiographic occlusion rates were quite similar ( $85 \%$ in the Cerecyte group versus $87 \%$ in the bare platinum group) with a retreatment rate of $4 \%$ at 6 months following treatment. $^{31}$

Another coil incorporating PGLA is the Nexus coil (ev3, Irvine, California), which has interwoven PGLA filaments attached. These have not been subjected to a randomized trial, but a single center study of 101 patients indicates that this coil did not favorably impact recurrence risk. ${ }^{32}$

HydroCoils (Terumo, Somerset, New Jersey) are platinum coils with an expanding hydrogel coiling, intended to increase packing attenuation ${ }^{33}$ but also found to promote tissue growth across the neck in rabbits. ${ }^{34}$ The HEAL registry, a multicenter nonrandomized prospective study of patients treated with $\mathrm{Hy}$ droCoil, investigated the safety and effectiveness of HydroCoils in patients with ruptured and unruptured intracranial aneurysms. ${ }^{35}$ The overall recanalization rate was $28.1 \%$, including a major recanalization rate of $19.2 \%$. The recanalization rate increased with larger aneurysm sizes: Small aneurysms had a recanalization rate of $8 \%$; large aneurysms, of $43 \%$, while the recanalization rate in giant aneurysms was as high as $80 \%$. There was suggestion of a benefit from HydroCoils in that patients treated in HEAL demonstrated a reduced recurrence rate when $>75 \%$ of the coil length used was HydroCoil and when the final coil was HydroCoil. ${ }^{35}$ HEAL did not show a direct correlation between packing attenuation and recurrence rates. ${ }^{35}$ When the packing attenuation was $\geq 50 \%$, the recurrence rate was $19 \%$, whereas for packing attenuation $<50 \%$, the recurrence rate was $18 \%$, suggesting that the improvement in recurrence rates with increased packing attenuation plateaus somewhere below $50 \%$

HELPS was a randomized multicentric trial comparing patients whose aneurysms were treated with HydroCoil with those treated with bare platinum coils. ${ }^{36}$ In the HELPS trial, the "major" recurrence rate at 18 months was $24 \%$ for aneurysms treated with HydroCoil versus $34 \%$ for those treated with bare platinum coils, yet the retreatment rate was only 3\% for aneurysms treated with either type of coil. ${ }^{36}$ Communicating hydrocephalus (diagnosed after a mean interval of 13.2 months) occurred in 5 patients treated with HydroCoil but in only 1 patient treated with bare platinum coils $(P=.012) .{ }^{36}$ In the Cerecyte trial, the retreatment rate was only $4 \%$ at 6 months for patients with ruptured aneurysms treated with either platinum coils or Cerecyte coils, ${ }^{31}$ which compares favorably with the $17 \%$ retreatment rate at 12 months in the ISAT trial. ${ }^{21}$ These findings suggest that retreatment rates have fallen considerably during the years between the completion of ISAT enrollment in 2002 and the completion of Cerecyte enrollment in 2009 (Table).

Another type of coil modification is to engineer different shape configurations and softness of platinum, which may allow higher packing attenuation. ${ }^{37-40}$ However, no high-quality data, to our knowledge, are available to support the clinical efficacy of this appealing theoretic concept. 
Retreatment rate in multicenter trials

\begin{tabular}{lcc}
\hline $\begin{array}{c}\text { Randomized Controlled Trials } \\
\text { (follow-up period) }\end{array}$ & $\begin{array}{c}\text { Enrollment } \\
\text { Period }\end{array}$ & $\begin{array}{c}\text { Retreatment } \\
\text { (\%) }\end{array}$ \\
\hline ISAT $^{59}(12 \mathrm{mo})^{\text {a }}$ & $1994-2002$ & $17 \%$ \\
HydroCoil, HELPS $^{36}$ (18 mo) & $2004-2007$ & $3 \%$ \\
Cerecyte $^{31}(6 \mathrm{mo})^{\mathrm{a}}$ & $2005-2009$ & $4 \%$ \\
Matrix, MAPS $^{30}(12 \mathrm{mo})$ & $2007-2009$ & $10 \%$ \\
\hline
\end{tabular}

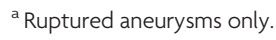

\section{Stent-Assisted Coil Embolization}

Since 2002, stents have been available as an adjunct to coils for the treatment of intracranial aneurysms. Several studies have reported instances of progressive occlusion of aneurysms treated with stents. ${ }^{12,41-44}$ Certainly, stent placement allows treatment of aneurysms that could not be treated with coils alone. As with balloon remodeling, stent placement allows operators to safely place coils that could not be placed without these adjunctive techniques, thus increasing packing attenuation. It has been proposed that stent-assisted coiling may decrease the rate of aneurysm recurrence after endovascular embolization. ${ }^{45}$ However, to evaluate the real impact of this adjunct on recurrence rates, a study comparing stent-assisted coil embolization with coil embolization alone for matched aneurysms would be necessary. In a series of 46 wide-neck aneurysms treated with adjunctive stent placement reported by Biondi et al, ${ }^{46}$ the overall recurrence was $18.2 \%$ with a retreatment rate equal to $15.2 \%$ at a mean of 8.8 months of followup. In a single-center series comparing outcomes for aneurysms treated with and without adjunctive stent placement, angiographic recanalization rates at an average time of 15 months were lower in the stented group (8.1\%) compared with the nonstented group $(37.5 \% ; P<.001) .{ }^{47}$

Another single-center study found no significant difference in recurrence rates between patients coiled with adjunctive stent placement and those coiled without stent placement, ${ }^{48}$ which may have been due to achievement of similar high packing attenuation by using the double-microcatheter technique and balloon remodeling in the patients not treated with stent placement. Stent placement might offer an indirect mechanism of reducing aneurysm recurrence by allowing greater packing attenuation. ${ }^{49}$ It remains unclear whether any improvement in long-term angiographic outcome is related to the placement of the stent itself or the improvement in coil placement afforded by the stent.

The use of stents in ruptured aneurysms is relatively contraindicated by the need for antiplatelet therapy with aspirin and clopidogrel. ${ }^{50}$ However, Tahtinen et $\mathrm{al}^{51}$ showed that stent-assisted coil embolization could be considered a feasible endovascular treatment option for ruptured wide-neck intracranial aneurysms that are difficult to treat with balloon-assisted embolization or surgical ligation.

\section{Flow Diversion}

A new generation of flexible self-expanding microcatheter-delivered stentlike devices with high metal surface area coverage is now available. ${ }^{52}$ Flow diverters achieve aneurysm occlusion by endoluminal reconstruction of the vessel wall of the parent artery. Shifting the blood flow away from the aneurysm neck, this device promotes the thrombosis of the aneurysm. In this way, recanalization could be avoided because the stability of the device within the parent artery establishes a stable hemodynamic environment that is less subject to displacement by blood flow. Complete angiographic occlusion was achieved in $56 \%$ and $95 \%$ of aneurysms at 3-6 and 12 months of radiologic follow-up. ${ }^{53}$ The incidence of hemorrhage after flow diversion was $2 \%$ in a prospective series. ${ }^{52}$ Aneurysm rupture occurring after flow diversion is usually catastrophic because of pretreatment with aspirin and clopidogrel that will be maintained for 3-6 months.

Immediate angiographic occlusion occurs in only $8 \%-21 \%$ of cases, ${ }^{54-56}$ but occlusion rates progress to as high as $95 \%$ at 1 year after treatment. ${ }^{55}$ While residual aneurysms do occur following flow-diversion therapy, recurrence and regrowth of aneurysms in the same manner that occurs following endovascular coil treatment have not been reported. However, late hemorrhages have been reported in some cases, including exceptionally delayed hemorrhages up to 5 months after flow diversion. ${ }^{57,58}$ As with adjunctive stent placement, the need for antiplatelet medications limits the use of flow-diversion devices in patients with ruptured aneurysms.

Almost no long-term data are available at this time regarding aneurysm recurrence after flow-diversion therapy, so it remains to be seen what impact this technology will have on this problem. Nonetheless, early results are encouraging, with flow-diversion devices offering hope of fewer recurrences in the future as well as offering a viable option for aneurysms that have previously recurred following treatment with coils. Many of the large aneurysms that are especially prone to recurrence with endovascular coil treatment are precisely the aneurysms for which flow-diversion seems to be most suitable, so there is a great potential for flow-diversion to significantly impact the problem of recurrence.

\section{CONCLUSIONS}

Aneurysm recurrences following endovascular therapy are a persistent problem, but incremental improvements have been made with devices and techniques developed during the past 2 decades. Modified coils have not really lived up to their potential, and platinum coils remain the mainstay of endovascular treatment. Perhaps the most progress has come about from improvements in initial angiographic results through the use of balloon remodeling, adjunctive stent placement, and a wider selection of coils. In the coming decade, we may see fewer recurrences due to increasing application of flow-diversion devices, but this technology is still relatively young and how widely applicable it will be remains to be seen.

Disclosures: Giuseppe Lanzino-UNRELATED: Other: Educational grants from Synthes* and ev3.* David Kallmes-UNRELATED: Grants/Grants Pending: ev3,* MicroVention," Micrus, ${ }^{*}$ NFocus, ${ }^{*}$ Sequent,* Patents (planned, pending, or issued): Spine-related patents, ${ }^{*}$ Royalties: spine fusion-related royalties, Payment for Development of Educational Presentations: CareFusion, ev3, Travel/Accommodations/Meeting Expenses Unrelated to Activities Listed: Microvention. * Harry CloftUNRELATED: Grants/Grants Pending: MindFrame, ${ }^{*}$ Cordis. *Money paid to the institution.

\section{REFERENCES}

1. Guglielmi G, Vinuela F, Duckwiler G, et al. Endovascular treatment of posterior circulation aneurysms by electrothrombosis using electrically detachable coils. J Neurosurg 1992;77:515-24

2. Murayama Y, Nien YL, Duckwiler G, et al. Guglielmi detachable coil 
embolization of cerebral aneurysms: 11 years' experience. J Neurosurg 2003;98:959-66

3. Raymond J, Guilbert F, Weill A, et al. Long-term angiographic recurrences after selective endovascular treatment of aneurysms with detachable coils. Stroke 2003;34:1398-403

4. Byrne JV, Sohn MJ, Molyneux AJ, et al. Five-year experience in using coil embolization for ruptured intracranial aneurysms: outcomes and incidence of late rebleeding. J Neurosurg 1999;90:656-63

5. Ferns SP, Sprengers ME, van Rooij WJ, et al. Coiling of intracranial aneurysms: a systematic review on initial occlusion and reopening and retreatment rates. Stroke 2009;40:e523-29

6. Gruber A, Killer M, Bavinzski G, et al. Clinical and angiographic results of endosaccular coiling treatment of giant and very large intracranial aneurysms: a 7-year, single-center experience. Neurosurgery 1999;45:793-803, discussion 803-04

7. Cognard C, Weill A, Spelle L, et al. Long-term angiographic follow-up of 169 intracranial berry aneurysms occluded with detachable coils. Radiology 1999;212:348-56

8. Plowman RS, Clarke A, Clarke M, et al. Sixteen-year single-surgeon experience with coil embolization for ruptured intracranial aneurysms: recurrence rates and incidence of late rebleeding: clinical article. J Neurosurg 2011;114:863-74

9. Gallas S, Januel AC, Pasco A, et al. Long-term follow-up of $\mathbf{1 0 3 6}$ cerebral aneurysms treated by bare coils: a multicentric cohort treated between 1998 and 2003. AJNR Am J Neuroradiol 2009;30:1986-92

10. Henkes H, Fischer S, Mariushi W, et al. Angiographic and clinical results in $\mathbf{3 1 6}$ coil-treated basilar artery bifurcation aneurysms. J Neurosurg 2005;103:990-99

11. Thornton J, Debrun GM, Aletich VA, et al. Follow-up angiography of intracranial aneurysms treated with endovascular placement of Guglielmi detachable coils. Neurosurgery 2002;50:239-49, discussion 249-50

12. Fiorella D, Albuquerque FC, McDougall CG. Durability of aneurysm embolization with Matrix detachable coils. Neurosurgery 2006;58: 51-59, discussion 51-59

13. Kawanabe Y, Sadato A, Taki W, et al. Endovascular occlusion of intracranial aneurysms with Guglielmi detachable coils: correlation between coil packing density and coil compaction. Acta Neurochir (Wien) 2001;143:451-55

14. Uchiyama N, Kida S, Nomura M, et al. Significance of volume embolization ratio as a predictor of recanalization on endovascular treatment of cerebral aneurysms with Guglielmi detachable coils. Interv Neuroradiol 2000;6(suppl 1):59-63

15. Sluzewski M, van Rooij WJ, Slob MJ, et al. Relation between aneurysm volume, packing, and compaction in 145 cerebral aneurysms treated with coils. Radiology 2004;231:653-58

16. Piotin M, Spelle L, Mounayer C, et al. Intracranial aneurysms: treatment with bare platinum coils-aneurysm packing, complex coils, and angiographic recurrence. Radiology 2007;243:500-08

17. Costalat V, Maldonado IL, Strauss O, et al. Toward accurate volumetry of brain aneurysms: combination of an algorithm for automatic thresholding with a 3D eraser tool. J Neurosci Methods 2011;198: 294-300

18. Taussky P, Kallmes DF, Cloft H. Mathematic analysis of incremental packing density with detachable coils: does that last coil matter much? AJNR Am J Neuroradiol 2012;33:E74-75

19. Pierot L, Cognard C, Anxionnat R, et al. Remodeling technique for endovascular treatment of ruptured intracranial aneurysms had a higher rate of adequate postoperative occlusion than did conventional coil embolization with comparable safety. Radiology 2011;258:546-53

20. Raymond J, Guilbert F, Weill A, et al. Follow-up of treated aneurysms: the challenge of recurrences and potential solutions. Neuroimaging Clin N Am 2006;16:513-23, ix

21. Campi A, Ramzi N, Molyneux AJ, et al. Retreatment of ruptured cerebral aneurysms in patients randomized by coiling or clipping in the International Subarachnoid Aneurysm Trial (ISAT). Stroke 2007;38:1538-44

22. Peluso JP, van Rooij WJ, Sluzewski M. Endovascular treatment of posterior circulation aneurysms. JBR-BTR 2007;90:547-49

23. Peluso JP, van Rooij WJ, Sluzewski M, et al. Posterior inferior cerebellar artery aneurysms: incidence, clinical presentation, and outcome of endovascular treatment. AJNR Am J Neuroradiol 2008;29: $86-90$

24. Ferns SP, Sprengers ME, van Rooij WJ, et al. Late reopening of adequately coiled intracranial aneurysms: frequency and risk factors in 400 patients with 440 aneurysms. Stroke 2011;42:1331-37

25. Hope JK, Byrne JV, Molyneux AJ. Factors influencing successful angiographic occlusion of aneurysms treated by coil embolization. AJNR Am J Neuroradiol 1999;20:391-99

26. Waldron JS, Halbach VV, Lawton MT. Microsurgical management of incompletely coiled and recurrent aneurysms: trends, techniques, and observations on coil extrusion. Neurosurgery 2009;64: 301-15, discussion 315-17

27. Ferns SP, van Rooij WJ, Sluzewski M, et al. Partially thrombosed intracranial aneurysms presenting with mass effect: long-term clinical and imaging follow-up after endovascular treatment. AJNR Am J Neuroradiol 2010;31:1197-205

28. Perrini P, Lanzino G. The association of venous developmental anomalies and cavernous malformations: pathophysiological, diagnostic, and surgical considerations. Neurosurg Focus 2006;21:e5

29. White PM, Raymond J. Endovascular coiling of cerebral aneurysms using "bioactive" or coated-coil technologies: a systematic review of the literature. AJNR Am J Neuroradiol 2009;30:219-26

30. Johnston SC, McDougal C, Gholkar A. On behalf of MAPS Steering Committee and Investigators: the MAPS trial-Matrix and Platinum Science-clinical trials. In: Proceedings of the Society of Neurointerventional Surgery, 8th Annual Meeting, Colorado Springs, Colorado; July 25-28, 2011

31. Molyneux A, Kerr R, Briley D, et al. Cerecyte Coil Trial. In: Proceeding of the 48th Annual Meeting of the American Society of Neuroradiology and the Neuroradiology Education and Research Foundation Symposium, Boston, Massachusetts; May 15-20, 2010

32. van Rooij WJ, de Gast AN, Sluzewski M. Results of 101 aneurysms treated with polyglycolic/polylactic acid microfilament Nexus coils compared with historical controls treated with standard coils. AJNR Am J Neuroradiol 2008;29:991-96

33. Cloft HJ, Kallmes DF. Aneurysm packing with HydroCoil Embolic System versus platinum coils: initial clinical experience. AJNR Am J Neuroradiol 2004;25:60-62

34. Ding YH, Dai D, Lewis DA, et al. Angiographic and histologic analysis of experimental aneurysms embolized with platinum coils, Matrix, and HydroCoil. AJNR Am J Neuroradiol 2005;26:1757-63

35. Cloft HJ. HydroCoil for Endovascular Aneurysm Occlusion (HEAL) study: 3-6 month angiographic follow-up results. AJNR Am J Neuroradiol 2007;28:152-54

36. White PM, Lewis SC, Gholkar A, et al. Hydrogel-coated coils versus bare platinum coils for the endovascular treatment of intracranial aneurysms (HELPS): a randomised controlled trial. Lancet 2011;377:1655-62

37. Quasar Grunwald I, Molyneux A, Kuhn AL, et al. Influence of coil geometry on intra-aneurysmal packing density: evaluation of a new primary wind technology. Vasc Endovascular Surg 2010;44:289-93

38. Wakhloo AK, Gounis MJ, Sandhu JS, et al. Complex-shaped platinum coils for brain aneurysms: higher packing density, improved biomechanical stability, and midterm angiographic outcome. AJNR Am J Neuroradiol 2007;28:1395-400

39. Sluzewski M, van Rooij WJ. Packing performance of helical Guglielmi detachable coil (GDC) 18 in intracranial aneurysms: a comparison with helical GDC 10 coils and complex Trufill/Orbit coils. AJNR Am J Neuroradiol 2007;28:1384-87

40. van Rooij WJ, Sluzewski M. Packing performance of GDC 360 degrees coils in intracranial aneurysms: a comparison with complex 
orbit coils and helical GDC 10 coils. AJNR Am J Neuroradiol 2007;28:368-70

41. Benitez RP, Silva MT, Klem J, et al. Endovascular occlusion of widenecked aneurysms with a new intracranial microstent (Neuroform) and detachable coils. Neurosurgery 2004;54:1359-67, discussion 1368

42. Pierot L, Bonafe A, Bracard S, et al. Endovascular treatment of intracranial aneurysms with Matrix detachable coils: immediate posttreatment results from a prospective multicenter registry. AJNR Am J Neuroradiol 2006;27:1693-99

43. Piotin M, Blanc R, Spelle L, et al. Stent-assisted coiling of intracranial aneurysms: clinical and angiographic results in 216 consecutive aneurysms. Stroke 2010;41:110-15

44. Yahia AM, Latorre JG, Gordon V, et al. Progressive occlusion of aneurysms in Neuroform stent-assisted treatment of intracranial aneurysms. J Neurol Neurosurg Psychiatry 2011;82:278-82. Epub 2010 Sep 22

45. Lubicz B, Bandeira A, Bruneau M, et al. Stenting is improving and stabilizing anatomical results of coiled intracranial aneurysms. Neuroradiology 2009;51:419-25

46. Biondi A, Janardhan V, Katz JM, et al. Neuroform stent-assisted coil embolization of wide-neck intracranial aneurysms: strategies in stent deployment and midterm follow-up. Neurosurgery 2007;61: $460-68$, discussion $468-69$

47. Lawson MF, Newman WC, Chi YY, et al. Stent-associated flow remodeling causes further occlusion of incompletely coiled aneurysms. Neurosurgery 2011;69:598-604

48. Hwang G, Park H, Bang JS, et al. Comparison of 2-year angiographic outcomes of stent- and nonstent-assisted coil embolization in unruptured aneurysms with an unfavorable configuration for coiling. AJNR Am J Neuroradiol 2011;32:1707-10. Epub 2011 Aug 18

49. Bendok BR, Parkinson RJ, Hage ZA, et al. The effect of vascular reconstruction device-assisted coiling on packing density, effective neck coverage, and angiographic outcome: an in vitro study. Neurosurgery 2007;61:835-40, discussion 840-41

50. Bodily KD, Cloft HJ, Lanzino G, et al. Stent-assisted coiling in acutely ruptured intracranial aneurysms: a qualitative, systematic review of the literature. AJNR Am J Neuroradiol 2011;32:1232-36. Epub 2011 May 5

51. Tahtinen OI, Vanninen RL, Manninen HI, et al. Wide-necked intracranial aneurysms: treatment with stent-assisted coil embolization during acute ( $<72$ hours) subarachnoid hemorrhage: experience in 61 consecutive patients. Radiology 2009;253:199-208

52. D'Urso PI, Lanzino G, Cloft HJ, et al. Flow diversion for intracranial aneurysms: a review. Stroke 2011;42:2363-68

53. Hassan T, Ahmed YM, Hassan AA. The adverse effects of flow-diverter stent-like devices on the flow pattern of saccular intracranial aneurysm models: computational fluid dynamics study. Acta Neurochir (Wien) 2011;153:1633-40

54. Byrne JV, Beltechi R, Yarnold JA, et al. Early experience in the treatment of intra-cranial aneurysms by endovascular flow diversion: a multicentre prospective study. PLoS One 2010;5: pii: e12492

55. Lylyk $P$, Miranda C, Ceratto R, et al. Curative endovascular reconstruction of cerebral aneurysms with the Pipeline embolization device: the Buenos Aires experience. Neurosurgery 2009;64:632-42, discussion 642-43, quiz N636

56. Szikora I, Berentei Z, Kulcsar Z, et al. Treatment of intracranial aneurysms by functional reconstruction of the parent artery: the $\mathrm{Bu}-$ dapest experience with the Pipeline embolization device. AJNR Am J Neuroradiol 2010;31:1139-47

57. Kulcsar Z, Houdart E, Bonafe A, et al. Intra-aneurysmal thrombosis as a possible cause of delayed aneurysm rupture after flow-diversion treatment. AJNR Am J Neuroradiol 2011;32:20-25

58. Cloft HJ. Flow diversion for cerebral aneurysms: a cautionary tale. AJNR Am J Neuroradiol 2011;32:26

59. Molyneux AJ, Kerr RS, Yu LM, et al. International subarachnoid aneurysm trial (ISAT) of neurosurgical clipping versus endovascular coiling in 2143 patients with ruptured intracranial aneurysms: a randomised comparison of effects on survival, dependency, seizures, rebleeding, subgroups, and aneurysm occlusion. Lancet 2005;366:809-17 